\title{
Stability-Indicating UHPLC Method for the Determination of Desvenlafaxine: Application to Degradation Kinetics
}

\author{
Halima Akter ${ }^{1}$, Md. Mahbubul Alam², Md. Rezoan Rabbi ${ }^{3}$ \\ and Abu Shara Shamsur Rouf ${ }^{2}$
}

\author{
${ }^{1}$ Department of Pharmacy, Faculty of Science, University of Comilla, Kotbari, Cumilla \\ ${ }^{2}$ Department of Pharmaceutical Technology, Faculty of Pharmacy, University of Dhaka, \\ Dhaka-1000, Bangladesh \\ ${ }^{3} 71$ Field Ambulance, Jessore Cantonment
}

(Received: July 15, 2021; Accepted: November 18, 2021; Published (web): December 26, 2021)

\begin{abstract}
This study was aimed to investigate the degradation behavior and physicochemical stability of desvenlafaxine using reversed-phase ultra-high-performance liquid chromatography (RP-UHPLC) system. The chromatogram was developed on Eclipse XDB-C8 column $(150 \times 4.6 \mathrm{~mm}, 5 \mu \mathrm{m})$. The eluents were monitored through a photo diode array plus (PDA+) detector at $210 \mathrm{~nm}$ using an isocratic method with a flow rate of $1.5 \mathrm{ml} / \mathrm{min}$. Mobile phase composition was 30:70 v/v mixture of $0.1 \%$ trifluoroacetic acid (TFA) in water and methanol. Forced degradation studies were performed on drug substance of desvenlafaxine as per International Conference on Harmonization (ICH) prescribed stressed conditions $(\mathrm{Q} 1 \mathrm{~A}(\mathrm{R} 2)$ and $\mathrm{Q} 1 \mathrm{~B})$ using hydrolytic (acidic, basic, and neutral), oxidative and photolytic methods. The drug substance was found highly labile to acidic $(0.5 \mathrm{~N}$ hydrochloric acid, $18.65 \%$ degradation in 2 hours at $\left.70^{\circ} \mathrm{C}\right)$, basic $(1.0 \mathrm{~N}$ sodium hydroxide, $11.01 \%$ degradation in 12 hours at $70^{\circ} \mathrm{C}$ ) and oxidative ( $3 \%$ hydrogen peroxide, $17.05 \%$ degradation in 2 hours at $50^{\circ} \mathrm{C}$ ) stressed conditions, but a great resistance was observed towards dry heat (maximum degradation $0.27 \%$ in 10 days from ambient to higher temperature, $80^{\circ} \mathrm{C}$ ), moist heat (maximum degradation $0.25 \%$ in 2 hours at $80^{\circ} \mathrm{C}$ and $75 \%$ relative humidity) as well as in photolytic degradation (maximum degradation $0.23 \%$ in 10 days at UV light of $315-400 \mathrm{~nm}$ ). A pseudo-first order kinetic was followed in acidic, basic and peroxide degradation methods which paved a way to calculate the half-life of the drug substance desvenlafaxine under ICH mentioned stressed conditions. The results were also statistically analyzed and the \% RSD values were compared with recommended guidelines.
\end{abstract}

Key words: Desvenlafaxine, RP-UHPLC, ICH, Force degradation, Pseudo-first order kinetic

\section{INTRODUCTION}

The ability of a drug substance or drug product to hold its physical, chemical, microbiological, toxicological, protective and informational specifications throughout the retest or expiration dating periods is defined as the stability of the drug substance or the drug product. ${ }^{1}$ The stability of chemical molecules in pharmaceutical sector affects the safety and efficacy of drug product which is a matter of great apprehension in this revolutionary era of pharmaceutical development. Polymorphism identification as well as determination of intrinsic stability of drug molecules and drug substances are

Correspondence to: Md. Mahbubul Alam

E-mail: mahabub22@du.ac.bd

Dhaka Univ. J. Pharm. Sci. 20(2): 167-176, 2021 (December) DOI: https://doi.org/10.3329/dujps.v20i2.57167 essential to predict possible reactions and degradation products in the development of a pharmaceutical formulation. ${ }^{2,3}$ They are necessary to determine and assure the identity, potency and purity of active ingredients as well as those of the formulated products. ${ }^{4}$ Data obtained are applied in developing a suitable manufacturing process, selecting proper packaging, storage conditions, product's shelf life and expiration dates as well as designing a product's life-cycle. ${ }^{5}$

Due to their possible composition, pharmaceuticals are especially sensitive to environmental factors. Precise storage conditions are necessary for the maintenance of quality as well as integrity and product activity. Additionally, some degradants of drug degradation processes are toxic 
and harmful to the patients. Thus, stability study also helps to correlate therapeutic effect with pharmacovigilence. ${ }^{4}$

The US FDA (Food and Drug Administration) and ICH guidance state the requirement of stability testing data to correlate the effects of environmental factors (temperature, humidity and light etc.) and quality of a product with time. So, drug stability is considered to be a secure way to ensure the delivery of therapeutic values to patients. ${ }^{6}$

Desvenlafaxine, the major active metabolite of venlafaxine, is an oral antidepressant of the serotonin-norepinephrine reuptake inhibitor (SNRI) class. Chemical name of desvenlafaxine is 4-[2(dimethylamino)-1-(1-hydroxycyclohexyl) ethyl] phenol with molecular formula $\mathrm{C}_{20} \mathrm{H}_{33} \mathrm{NO}_{7}$ and molecular weight of $399.5 \mathrm{~g} / \mathrm{mol}$. The clinical effect of desvenlafaxine is thought to occur via inhibition of neurotransmitter reuptake in serotonin, norepinephrine, and dopamine transporters. ${ }^{7}$

It inhibits serotonin transporters with 10 times the affinity of norepinephrine transporters, and dopamine transporters with the lowest affinity. This drug substance has no inhibitory effect on monoamine oxidase, and almost no affinity for muscarinic, cholinergic, H1-histaminergic, and alpha1-adrenergic receptors in vitro. ${ }^{7}$

There is no official current analytical monograph for powder or dosage forms of desvenlafaxine in the monograph like the British Pharmacopeia or the United States Pharmacopeia. Only few reports were found in the current literature for the quantitative determination of desvenlafaxine through UV spectrophotometry, UHPLC, HPTLC and RP-HPLC techniques. ${ }^{8-13}$ But most of these reported methods were less suitable for routine analysis due to poor resolution, complex mobile phase (buffers) preparation, higher retention time which results in extended run time. Furthermore, there is no reported study on the degradation kinetics of this drug molecule. So, the aim of the present work is to develop an accurate, sensitive and rapid RP-UHPLC method using simple mobile phase composition for routine analysis of desvenlafaxine as well as to study its detailed stressed conditions outcomes and degradation kinetics as a part of continued research work on the development, validation and force degradation of other molecules. ${ }^{14-17}$

\section{MATERIALS AND METHODS}

Chemicals and reagents. Standard desvenlafaxine was provided as a generous gift from Incepta Pharmaceuticals Limited, Bangladesh. HPLC grade methanol was procured from Merck, USA. Analytical grade TFA and $\mathrm{H}_{2} \mathrm{O}_{2} \quad(30 \%)$ were procured from Panreac Qumica Sau, Spain, Spain and Scharlau, Spain respectively. $\mathrm{NaOH}$ pellets were obtained from Merck, India whereas, $\mathrm{HCl}(37 \%)$ and acetone were purchased from Merck, Germany. Water (HPLC grade) was prepared from Millipore Milli-Q water purification system from Evoqua Water Technologies, USA. Other materials and reagents were of analytical grade.

Chromatographic condition. Chromatographic system used for the investigation was RP-UHPLC Perkin Elmer-flexer series (PerkinElmer Inc., USA) along with FX-15 binary pump, detector and SIL/20A auto-sampler. Chromera software was affiliated with the integrated system for data recovery. Eclipse XDB-C8 column $(150$ x $4.6 \mathrm{~mm}$ i.d., $5 \mu \mathrm{m}$ particle size) was involved in the chromatographic separation of the eluents in an isocratic mode with a flow rate of $1.5 \mathrm{ml} / \mathrm{min}$ at detection length of $210 \mathrm{~nm}$. A $20 \mu \mathrm{l}$ sample was injected into the column with oven temperature fixed at $25^{\circ} \mathrm{C}$. The mobile phase was a homogenous mixture of $0.1 \%$ TFA in water and methanol in the ratio of 30:70 v/v which was also used as diluting solution in this experiment. It was filtered using vacuum pump and nylon membrane filter of $0.45 \mu \mathrm{m}$ (Restek, USA) following sonication with sonicator of Human lab Instrument Co., South Korea and degassing. Before injecting into the chromatographic system, all samples were passed through syringe filter of $0.2 \mu \mathrm{m}$.

Preparation of standard solutions. Accurately weighed quantity $(25.0 \mathrm{mg})$ of standard desvenlafaxine by electronic balance (Shimadzu, 
Japan) was transferred to a $25.0 \mathrm{ml}$ volumetric flask and dissolved in $10 \mathrm{ml}$ of the diluting medium (same as mobile phase composition) and sonicated for 10 minutes. The volume was made up to the mark with mobile phase to get the final concentration of 1 $\mathrm{mg} / \mathrm{ml}$. As per requirement, five solutions of concentration $80 \mu \mathrm{g} / \mathrm{ml}, 90 \mu \mathrm{g} / \mathrm{mL} 100 \mu \mathrm{g} / \mathrm{ml}, 110$ $\mu \mathrm{g} / \mathrm{ml}$ and $120 \mu \mathrm{g} / \mathrm{ml}$ were prepared with proper dilution with the diluting solution.

Validation of the proposed method. The developed method was validated according to current pharmaceutical regulatory guidelines ICH Q2(R1).

System suitability. To validate system suitability, the peak area, theoretical plates, tailing factor and retention time of six replicate injections of working standard of desvenlafaxine of nominal concentration $(100 \mu \mathrm{g} / \mathrm{ml})$ were used. Percentage relative standard deviation (\% RSD) values were calculated in each case.

Linearity. For linearity, five different concentrations of standard solution of the drug substance (range 80-120 $\mu \mathrm{g} / \mathrm{ml}$ ) were analyzed and calibration curve was built. Regression line was calculated as $\mathrm{y}=\mathrm{mx}+\mathrm{c}$, where, $\mathrm{y}, \mathrm{m}, \mathrm{x}$ and $\mathrm{c}$ represent the response (peak area expressed as $\mathrm{mAU}$ ), the slope of the regression line, the concentration of desvenlafaxine in $\mu \mathrm{g} / \mathrm{ml}$ and the intercept of the regression line respectively.

Specificity. Blank along with spiked sample analysis were performed to determine the specificity of the developed method. A blank sample consisting of mobile phase was prepared and treated in the same manner as the investigational spiked samples.

Accuracy (recovery test). Accuracy was evaluated by percent recoveries (mean $\pm \%$ RSD) from six replicates of standard solution of nominal concentration $(100 \mu \mathrm{g} / \mathrm{ml})$ of desvenlafaxine.

Precision. To study the precision of the developed method, repeatability (intraday precision) and intermediate precision (inter-day precision) were calculated and to do so nominal concentration (100 $\mu \mathrm{g} / \mathrm{ml}$ ) of desvenlafaxine standard solution was analyzed in six replicates on the same day (intra-day precision) and daily for six times over a period of three days (inter-day precision) and \% RSD were compared accordingly.

Sensitivity. Limits of detection (LOD) and limits of quantitation (LOQ) were calculated based on signal to noise ratio of chromatogram. Pump pressure was monitored and when the fluctuation was negligible, highly diluted standard solutions of desvenlafaxine were injected. LOD and LOQ were the concentrations where the peak area of the chromatogram was about 3.3 times and 10 times higher than the signal to noise ratio.

Ruggedness. Ruggedness of the method was determined by analyzing six replicates of nominal standard concentration of desvenlafaxine $(100 \mu \mathrm{g} / \mathrm{ml})$ by two analysts to check the reproducibility of the test results. For both cases, the percentage recovery and $\%$ RSD were calculated.

Robustness. Robustness of the method was investigated by evaluating the effect of flow rate (1.4, $1.5,1.6 \mathrm{ml} / \mathrm{min})$ and mobile phase composition (0.1 $\%$ TFA in water: methanol $=35: 65 ; 30: 70 ; 25: 75$ $\mathrm{v} / \mathrm{v})$. Under these conditions, \% RSD were calculated from obtained peak areas of respective chromatograms of three replicates.

Force degradation analysis. $100 \mathrm{ml}$ of drug solution having concentration of $100 \mu \mathrm{g} / \mathrm{ml}$ was subjected to stress degradation under acidic $(0.5 \mathrm{~N}$ $\mathrm{HCl}, 5 \mathrm{ml}, 70^{\circ} \mathrm{C}, 2$ hours), alkaline $(1 \mathrm{~N} \mathrm{NaOH}, 5$ $\mathrm{mL}, 70^{\circ} \mathrm{C}, 12$ hours), oxidative hydrolysis $\left(3 \% \mathrm{H}_{2} \mathrm{O}_{2}\right.$, $5 \mathrm{ml}, 50^{\circ} \mathrm{C}, 2$ hours) and neutral hydrolytic conditions by refluxing at thermal stress $\left(80^{\circ} \mathrm{C}, 75 \%\right.$ $\mathrm{RH}, 2$ hours). Dry heat and photolytic stress were experienced by placing the intact drug substance powder in aluminium foil and kept it in dryer $\left(80^{\circ} \mathrm{C}\right.$, 10 days) and photo stability chamber of ACMAS Technologies Pvt. Ltd., India (315-400 nm, 10 days), respectively. The aforementioned forced conditions i.e. strength of stress chemicals and temperature of stress conditions were chosen since, in milder ambience the drug substance illustrated trivial degradation. All force degradation samples were prepared in similar fashion as of method validation sample preparation. Stability of the standard stock 
solution of drug substance was tested by storing at room temperature for 24 hours and analyzing the sample on RP-UHPLC in every 2 hours interval.

\section{RESULTS AND DISCUSSION}

Validation of analytical method. The method was validated with respect to system suitability (tailing factor $1.149 \pm 0.71$, theoretical plate 5703.53 \pm 0.37 and retention time $2.333 \pm 0.15$ ), accuracy with a percentage recovery of $99.256 \pm 0.960 \%$ to $100.047 \pm 0.036 \%$ and intraday and inter-day precision of $100.013 \pm 0.073$ and $99.943 \pm 0.442$, respectively (Tables 1-3). While in table 4 results of robustness study in terms of intentional deviation in flow rate and mobile phase composition showed a percentage recovery of $99.837 \pm 0.026$ to $100.182 \pm$ 0.025 and $100.01 \pm 0.17$ to $100.085 \pm 0.026$, respectively. Moreover, $99.915 \pm 0.12$ to $99.982 \pm$ 0.068 percentage recoveries were found to back up the ruggedness study results of the developed method. Linearity in terms of correlation coefficient $\left(\mathrm{R}^{2}\right)$ was found 0.9999 over the concentration range of $80-120 \mu \mathrm{g} / \mathrm{ml}$ (Fig. 1). In the chromatogram of blank sample good resolution was obtained and no interference of peaks was observed (Fig. 2). The sensitivity of the method was determined through several trials with diluted solution of standard desvenlafaxine and the LOD and LOQ values were obtained at $0.8 \mu \mathrm{g} / \mathrm{ml}$ and $2.4 \mu \mathrm{g} / \mathrm{ml}$, respectively. The method was proved to be rugged and robust since \% recovery as well as \% RSD were within ICH Q2(R1) prescribed conditions. The developed validated method was easier and non-cumbersome with regards to mobile phase preparation, while the other published methods used complex mobile phase prepared with potassium dihydrogen phosphate $\left(\mathrm{KH}_{2} \mathrm{PO}_{4}\right)$ buffer, methanol and acetonitrile, ${ }^{12} 2 \%$ triethylamine in $0.05 \mathrm{M}$ ammonium acetate and methanol. ${ }^{11}$ It has been proved to be rapid with lower retention time (2.333 minutes) and lesser run time eventually which supports the superiority of this developed process over other methods such as Mallikarjuna's and Huma Rao's published methods in terms of retention time and run time. ${ }^{12,18}$ The sensitivity of the method was also superior comparing with Huma Rao's reported method. ${ }^{18}$

Table 1. Outcomes of system suitability parameters $(n=6$, where $n$ implies the replicate number of sample injection).

\begin{tabular}{lll}
\hline Parameters & Value (Mean $\pm \%$ RSD) & Acceptable Limit \\
\hline Peak Area & $1834828.31 \pm 0.27$ & $\%$ RSD $\leq 1$ \\
Tailing Factor & $1.149 \pm 0.71$ & $\leq 2.0$ \\
Theoretical Plate & $5703.53 \pm 0.37$ & $>2000$ \\
Retention Time & $2.333 \pm 0.15$ & $\%$ RSD $\leq 0.5$ \\
\hline
\end{tabular}

Table 2. Result of accuracy study ( $n=3$, where $n$ implies the replicate number of sample injection).

\begin{tabular}{cc}
\hline $\begin{array}{c}\text { Amount Added } \\
(\mu \mathrm{g} / \mathrm{ml})\end{array}$ & $\begin{array}{c}\% \text { Recovery } \\
(\text { Mean } \pm \% \text { RSD })\end{array}$ \\
\hline 80 & $100.004 \pm 0.034$ \\
90 & $99.991 \pm 0.047$ \\
100 & $99.998 \pm 0.018$ \\
110 & $100.047 \pm 0.036$ \\
120 & $99.256 \pm 0.960$ \\
\hline
\end{tabular}

Forced degradation and stability-indicating study of desvenlafaxine. Under different stress conditions, concentration of the drug substance decreased significantly with the formation of different degradation products in case of acid $(0.5 \mathrm{~N}$ $\mathrm{HCl}, 18.65 \%$ degradation in 2 hours at $70^{\circ} \mathrm{C}$ ), base $(1.0 \mathrm{~N} \mathrm{NaOH}, 11.01 \%$ degradation in 12 hours at $\left.70^{\circ} \mathrm{C}\right)$ and oxidative $\left(3 \% \mathrm{H}_{2} \mathrm{O}_{2}, 17.05 \%\right.$ degradation in 2 hours at $50^{\circ} \mathrm{C}$ ) hydrolysis (Figures 3-5). However, an eminent resistance was experienced in dry heat (maximum degradation $0.27 \%$ in 10 days from ambient to higher temperature, $80^{\circ} \mathrm{C}$ ), moist heat (maximum degradation $0.25 \%$ in 2 hours at $80^{\circ} \mathrm{C}$ and $75 \%$ relative humidity) as well as in photolytic degradation (maximum degradation 0.23 $\%$ in 10 days at UV light of 315-400 nm) (Figure 6). Table 5 shows the percentage degradation of desvenlafaxine under different stress conditions. 
Table 3. Findings of precision study ( $n=6$, where $n$ implies the replicate number of sample injection).

\begin{tabular}{|c|c|c|c|c|c|}
\hline \multirow{2}{*}{$\begin{array}{l}\text { Amount } \\
\text { added } \\
(\mu \mathrm{g} / \mathrm{ml})\end{array}$} & \multirow[t]{2}{*}{$\begin{array}{l}\text { Intra-day } \% \text { recovery } \\
(\text { Mean } \pm \% \text { RSD) }\end{array}$} & \multicolumn{3}{|c|}{$\begin{array}{c}\text { Inter-day } \\
(\% \text { Recovery } \pm \% \text { RSD }) \\
\end{array}$} & \multirow{2}{*}{$\begin{array}{l}\text { Inter-day } \\
\% \text { recovery } \\
(\text { Mean } \pm \% \text { RSD) }\end{array}$} \\
\hline & & Day 1 & Day 2 & Day 3 & \\
\hline 100 & $100.013 \pm 0.073$ & $\begin{array}{l}100.019 \pm \\
0.073\end{array}$ & $99.937 \pm 0.054$ & $99.874 \pm 0.065$ & $99.943 \pm 0.442$ \\
\hline
\end{tabular}

Table 4. Result of robustness \& ruggedness study (in terms of flow rate, mobile phase composition and analyst variation).

\begin{tabular}{lllllll}
\hline Study Type & Parameters & $\begin{array}{l}\text { Variations } \\
(\mathrm{ml} / \mathrm{min})\end{array}$ & $\begin{array}{l}\text { Amount added } \\
(\mu \mathrm{g} / \mathrm{ml})\end{array}$ & Peak area & $\begin{array}{l}\text { Retention } \\
\text { time }(\mathrm{min})\end{array}$ & $\begin{array}{l}\text { \% Recovery } \\
(\mathrm{Mean} \pm \% \mathrm{RSD})\end{array}$ \\
\hline & $\begin{array}{l}\text { Mobile phase flow rate } \\
(\mathrm{ml} / \mathrm{min})\end{array}$ & 1.4 & 100 & 1831794.7 & 2.496 & $99.837 \pm 0.026$ \\
& & 1.5 & 100 & 1835342 & 2.330 & $100.03 \pm 0.052$ \\
Robustness & & 1.6 & 100 & 1838124.7 & 2.160 & $100.182 \pm 0.025$ \\
\cline { 2 - 7 } Study(n=3) & $\begin{array}{l}\text { Mobile phase composition } \\
\text { \% Methanol: \% TFA) }\end{array}$ & $68: 32$ & 100 & 1830395 & 2.434 & $100.01 \pm 0.17$ \\
& & $70: 30$ & 100 & 1835470.3 & 2.331 & $100.03 \pm 0.056$ \\
& & $72: 28$ & 100 & 1835672 & 2.276 & $100.085 \pm 0.026$ \\
\hline $\begin{array}{l}\text { Ruggedness } \\
\text { Study (n=6) }\end{array}$ & Analyst variation & Analyst 1 & 100 & 18303951 & 2.334 & $99.982 \pm 0.068$ \\
\hline
\end{tabular}

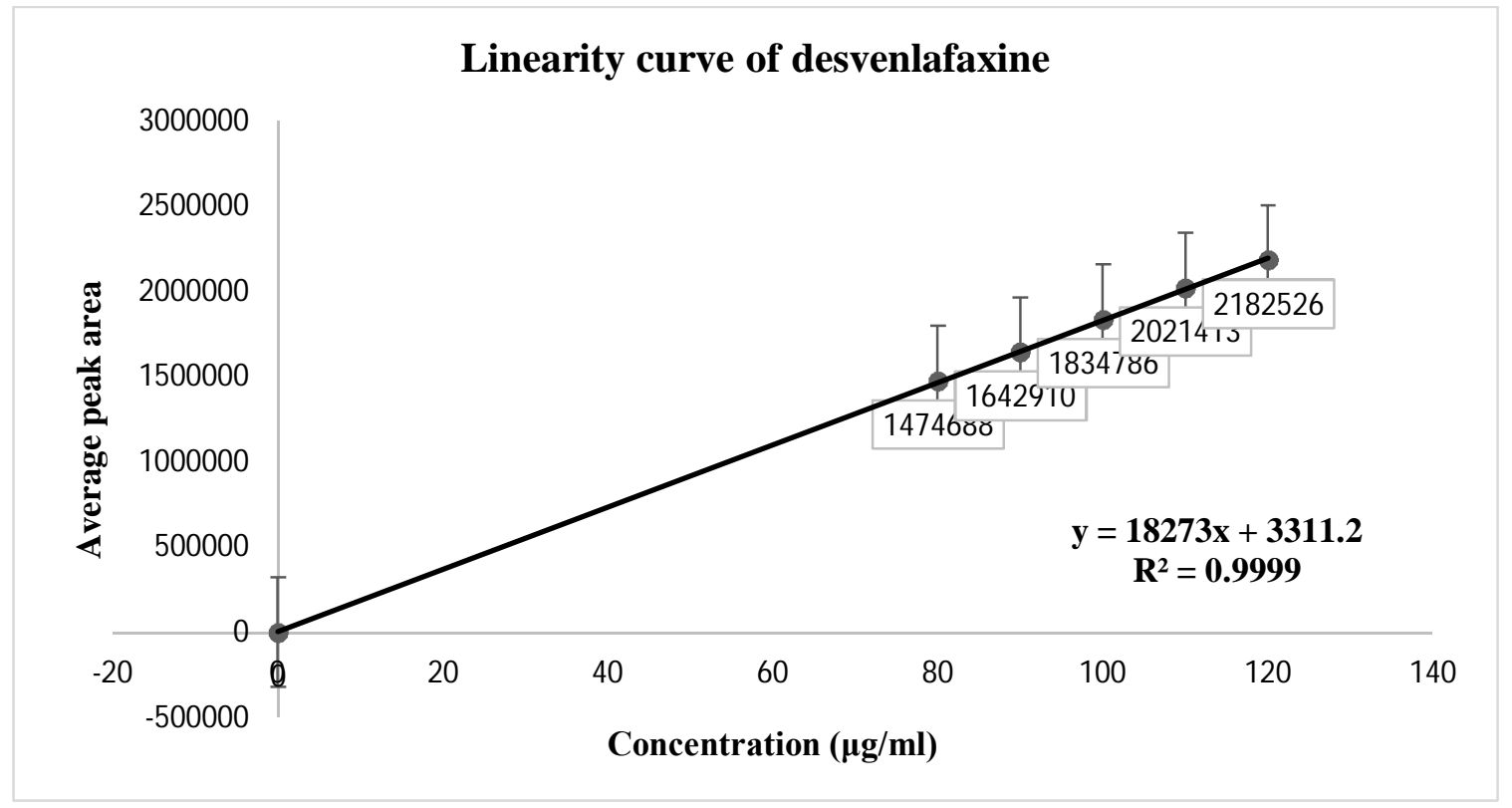

Figure 1. Linearity curve of desvenlafaxine ranging from 80 to $120 \mu \mathrm{g} / \mathrm{ml}$ (Each point represents the mean of 6 determinations). 
Figure 2. Chromatogram of blank sample.

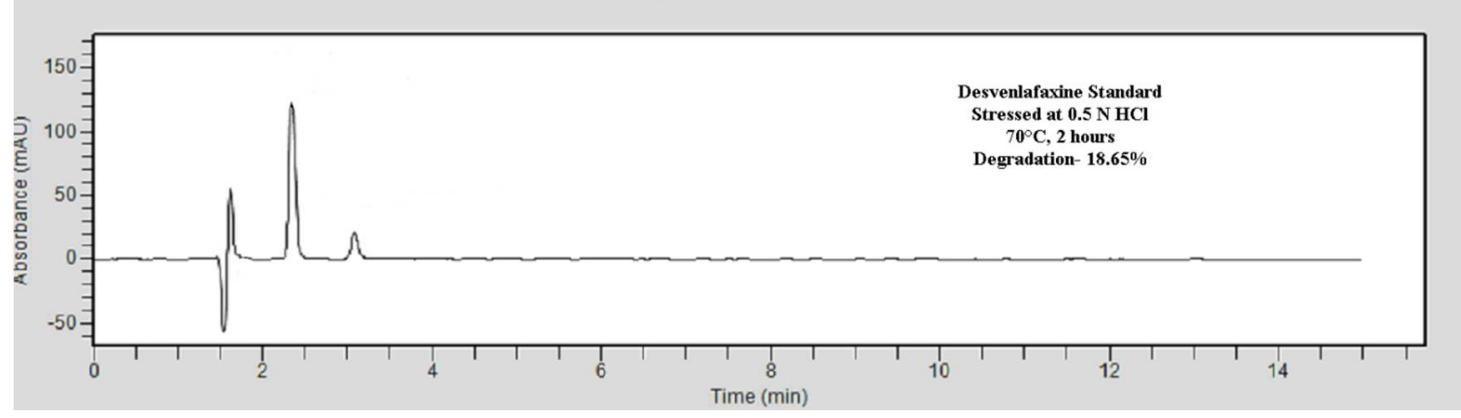

Figure 3. Chromatogram of desvenlafaxine, stressed in $0.5 \mathrm{~N} \mathrm{HCl}$ at $70^{\circ} \mathrm{C}$ for 2 hours.

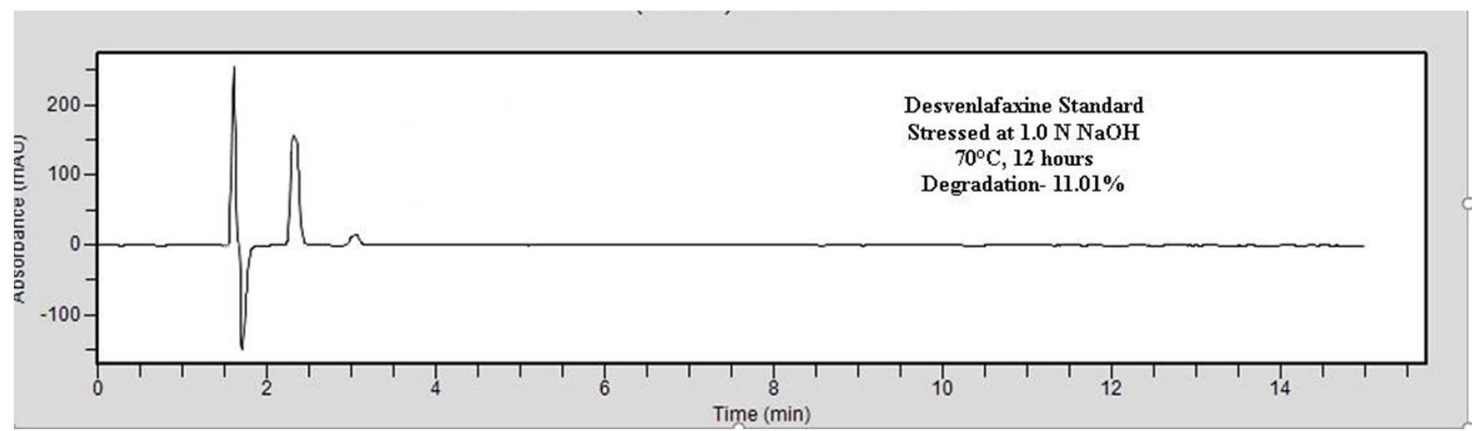

Figure 4. Chromatogram of desvenlafaxine, stressed in $1.0 \mathrm{~N} \mathrm{NaOH}$ at $70^{\circ} \mathrm{C}$ for 12 hours.

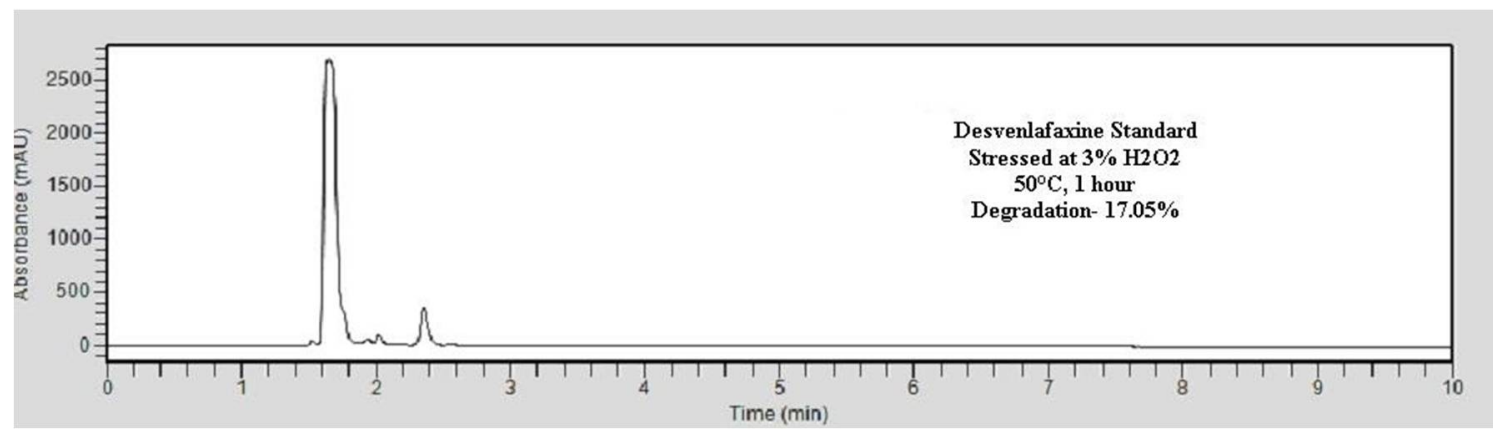

Figure 5. Chromatogram of desvenlafaxine, stressed in $3 \% \mathrm{H}_{2} \mathrm{O}_{2}$ at $50^{\circ} \mathrm{C}$ for 2 hours. 


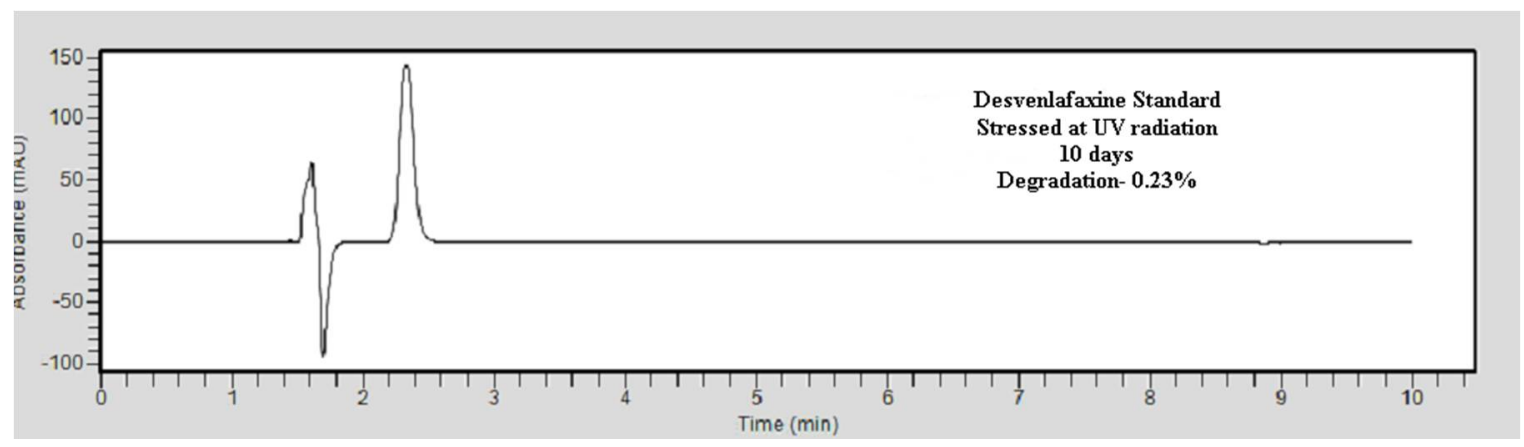

Figure 6. Chromatogram of desvenlafaxine, stressed in UV light for 10 days.

Table 5. Results of stress degradation studies of desvenlafaxine ( $n=6$, where $n$ implies the replicate number of sample injection).

\begin{tabular}{lllll}
\hline $\begin{array}{l}\text { Sl. } \\
\text { No }\end{array}$ & Stress conditions & Time & $\begin{array}{l}\% \text { Recovery } \\
(\text { Mean } \pm \% \text { RSD })\end{array}$ & $\begin{array}{l}\% \text { Degradation } \\
(\text { Mean } \pm \% \text { RSD })\end{array}$ \\
\hline 1 & Acid Degradation & 2 hours & $81.55 \pm 0.33$ & $18.45 \pm 0.33$ \\
2 & Base Degradation & 12 hours & $88.13 \pm 0.21$ & $11.87 \pm 0.21$ \\
3 & Peroxide Degradation & 2 hours & $86.11 \pm 0.34$ & $13.89 \pm 0.43$ \\
4 & UV Degradation & 10 days & $99.77 \pm 0.22$ & $0.23 \pm 0.22$ \\
5 & Thermal Degradation (Dry Heat) & 10 days & $99.73 \pm 0.43$ & $0.27 \pm 0.43$ \\
6 & Thermal Degradation (Moist Heat) & 2 hours & $99.75 \pm 0.17$ & $0.25 \pm 0.17$ \\
\hline
\end{tabular}

Acidic and basic hydrolytic degradation of the molecule were investigated at room temperature, $50^{\circ} \mathrm{C}$ and $70^{\circ} \mathrm{C}$; but at room temperature and $50^{\circ} \mathrm{C}$, the rate of hydrolysis was so slow that no notable degradation was achieved. In acidic degradation, strength of $\mathrm{HCl}$ was increased up to $0.5 \mathrm{~N}$ where negligible degradation occurs at lower concentrations. Whereas, the strength of $\mathrm{NaOH}$ was increased up to $1.0 \mathrm{~N}$ to get significant amount of degradation. Thus, $0.5 \mathrm{~N} \mathrm{HCl}$ was used for acid

Acidic hydrolysis

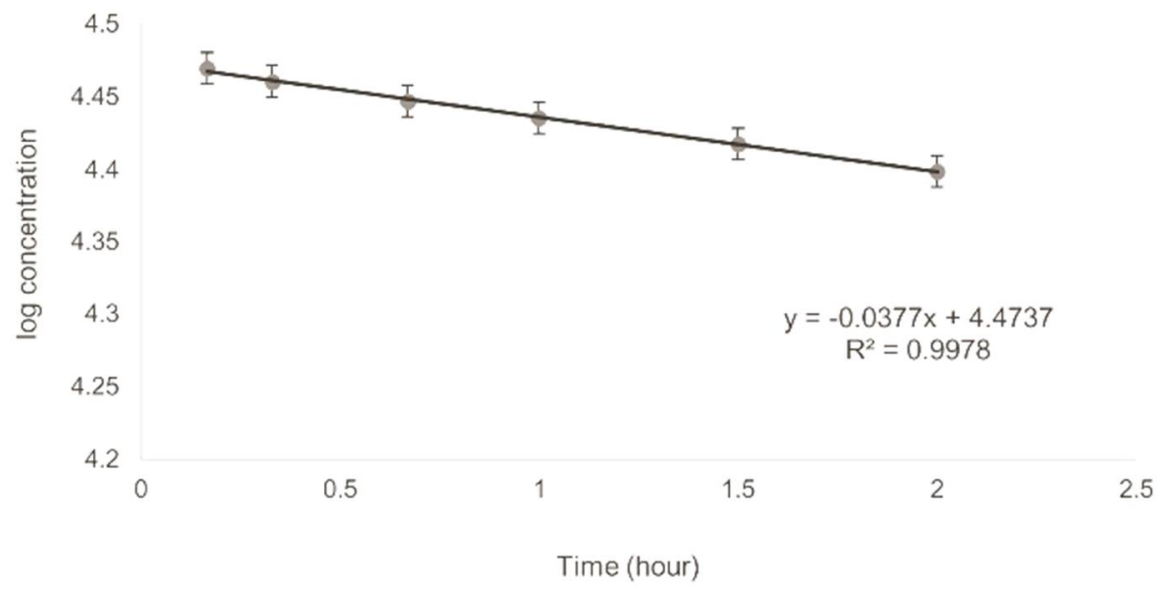

Figure 7. Desvenlafaxine degradation kinetics at $70^{\circ} \mathrm{C}$ under $0.5 \mathrm{~N} \mathrm{HCl}$ stressed conditions. 


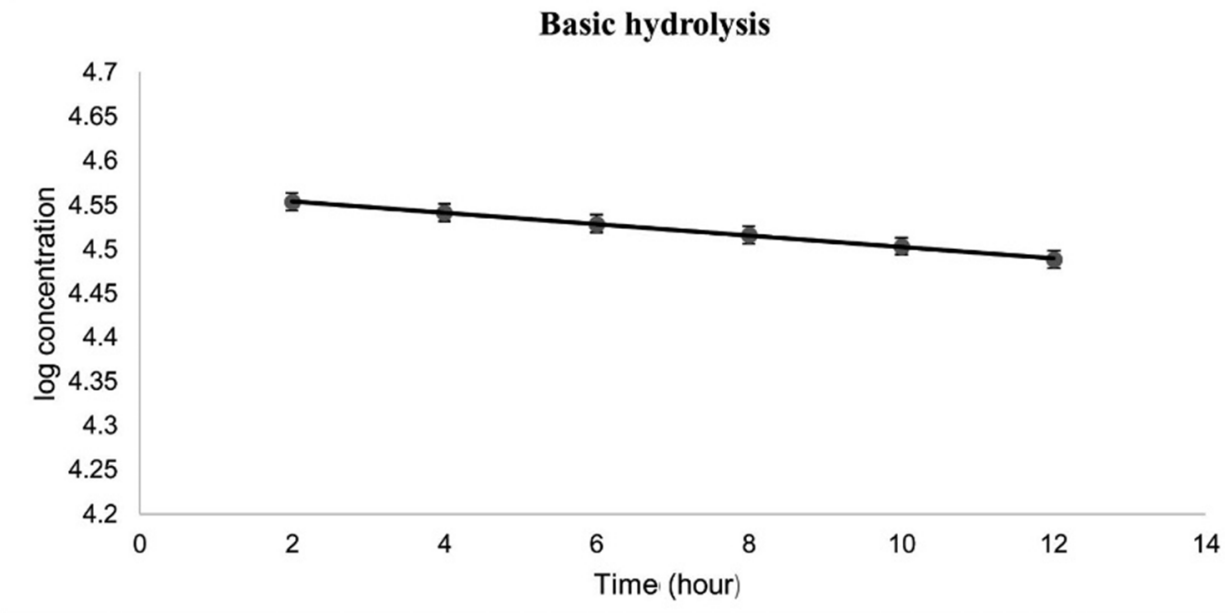

Figure 8. Desvenlafaxine degradation kinetics at $70^{\circ} \mathrm{C}$ under $1.0 \mathrm{~N} \mathrm{NaOH}$ stressed conditions.

Table 6. Results of degradation kinetics study for acidic, basic, peroxide hydrolysis ( $n=6$, where $n$ implies the replicate number of sample injection).

\begin{tabular}{|c|c|c|c|c|}
\hline Conditions & Time (h=hour) & Concentration $(\log \mathrm{C}), \mu \mathrm{g} / \mathrm{ml}$ & $\%$ Degradation & Rate constant $(\mathrm{k}), \mathrm{h}^{-1}$ \\
\hline \multirow{6}{*}{$0.5 \mathrm{~N} \mathrm{HCl}$} & 0.167 & 87.31 & 12.69 & \multirow{6}{*}{0.0868} \\
\hline & 0.33 & 86.52 & 13.48 & \\
\hline & 0.67 & 85.37 & 14.63 & \\
\hline & 1 & 84.4 & 15.60 & \\
\hline & 1.5 & 82.89 & 17.11 & \\
\hline & 2 & 81.35 & 18.65 & \\
\hline \multirow{6}{*}{$1.0 \mathrm{~N} \mathrm{NaOH}$} & 2 & 94.98 & 5.02 & \multirow{6}{*}{0.01497} \\
\hline & 4 & 93.83 & 6.17 & \\
\hline & 6 & 92.65 & 7.35 & \\
\hline & 8 & 91.48 & 8.52 & \\
\hline & 10 & 90.32 & 9.68 & \\
\hline & 12 & 88.99 & 11.01 & \\
\hline \multirow{6}{*}{$3 \% \mathrm{H}_{2} \mathrm{O}_{2}$} & 0.137 & 88.37 & 11.63 & \multirow{6}{*}{0.0783} \\
\hline & 0.33 & 87.72 & 12.28 & \\
\hline & 0.67 & 86.61 & 13.39 & \\
\hline & 1 & 85.52 & 14.48 & \\
\hline & 1.5 & 84.23 & 15.77 & \\
\hline & 2 & 82.95 & 17.05 & \\
\hline
\end{tabular}

hydrolysis, whereas $1.0 \mathrm{~N} \mathrm{NaOH}$ was used for the basic hydrolysis degradation kinetic study. In case of oxidation with $\mathrm{H}_{2} \mathrm{O}_{2}$, the degradation kinetics was studied at $50^{\circ} \mathrm{C}$ with $3 \%$ concentration (Figure 5) showing notable decomposition rate. In all tested kinetic studies, the degradation followed pseudo-first order kinetics as log concentration of percent remaining drug substance vs time depicted a straight line (Figures 7-9). 
The degradation rate constants were calculated (Table 6) from the slopes of the straight lines according to $\log \mathrm{C}=\log \mathrm{C}_{0}-\mathrm{Kt} / 2.303$; where, the slope of the line is $-\mathrm{K} / 2.303$ (here, $\mathrm{K}$ is the degradation rate constant) and $\mathrm{C}$ and $\mathrm{C}_{0}$ are the drug concentrations measured at a given time $\mathrm{t}$ and at zero time (in hour), respectively. ${ }^{19,20}$ The found rate constants can be used to determine the half-lives of the drug in stressed conditions as there is no reported data found in this field.

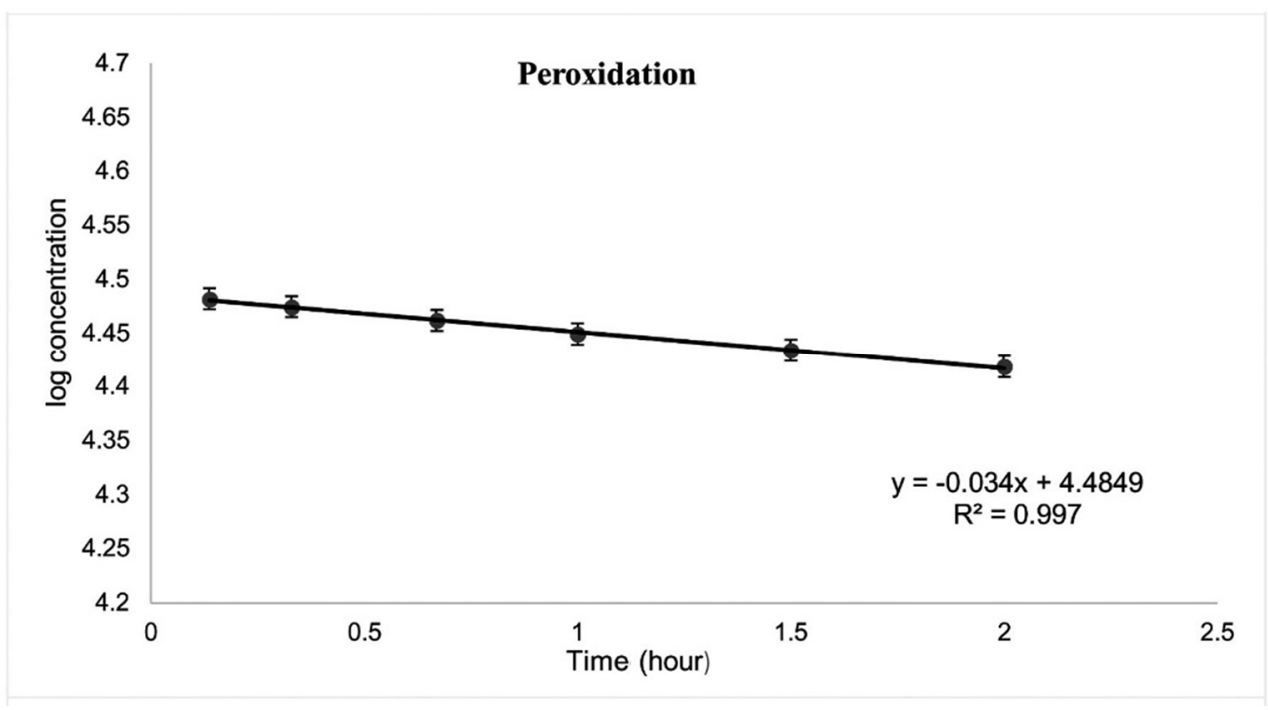

Figure 9. Desvenlafaxine degradation kinetics at $50^{\circ} \mathrm{C}$ under $3 \% \mathrm{H}_{2} \mathrm{O}_{2}$ stressed conditions.

\section{CONCLUSION}

The newly developed method has been proven to be simple, sensitive, rapid and versatile for the determination of desvenlafaxine in the presence of its degradation products, to calculate its degradation kinetics rates and half-lives at different stressed conditions according to ICH guideline. In this study the drug exhibited degradation under acidic $(0.5 \mathrm{~N}$ $\mathrm{HCl})$, alkaline $(1.0 \mathrm{~N} \mathrm{NaOH})$ and oxidative $(3 \%$ $\mathrm{H}_{2} \mathrm{O}_{2}$ ) stressed conditions, following a pseudo-firstorder degradation kinetics behavior. But, it was found to be stable under thermal and photolytic accelerated stressed conditions. The mobile phase composition was simple with commonly available and inexpensive reagents which render the method suitable for routine analysis as well as further research on desvenlafaxine.

\section{AUTHORS' CONTRIBUTIONS}

The idea was generated and supervised by ASSR. The laboratory work was performed by HA with active assistance of MMA. The statistical analysis was performed by MRR. HA, MMA and MRR drafted the manuscript and was finally approved by ASSR.

\section{CONFLICT OF INTERESTS}

The authors declare no conflicts of interest.

\section{REFERENCES}

1. Kommanaboyina, B. and Rhodes, C.T. 1999. Trends in stability testing, with emphasis on stability during distribution and storage. Drug Dev. Ind. Pharm. 25, 857-868.

2. Silva, K.E.R., Alves, L.D.S., Soares, M.F.R., Passos, R.C.S., Faria, A.R. and Neto, P.R. 2009. Modelos de avaliação da estabilidade de fármacos e medicamentos para a indústria farmacêutica. Rev Ciênc Farm Báica Apl. 30, 129-135

3. Singh, J., 2015. International conference on harmonization of technical requirements for registration of pharmaceuticals for human use. J. Pharmacol. Pharmacother. 6, 185-187.

4. Singh, S. and Bakshi, M., 2000. Guidance on the conduct of stress tests to determine inherent stability of drugs. Pharm. Technol. Asia. 24-24. This article was retrieved from https://go.gale.com/ps/i.do?id=GALE\%7CA68156110\&sid= googleScholar $\& v=2.1 \& i t=r \&$ linkaccess $=a b s \& i s s n=1753901$ $3 \& \mathrm{p}=\mathrm{AONE} \& \mathrm{sw}=\mathrm{w}$ 
5. Thompson, J.E. and Davidow, L.W. 2016. A prática farmacêutica na manipulação de medicamentos. Artmed Editora. This book was retrieved from https://books.google.com/books?hl=en\&lr=\&id=swKpDAA AQB AJ\&oi=fnd\&pg=PA1 \&dq=Thompson,+J.E.+and+David ow,+L.W.+2016.+A+pr\%C3\%A1tica+farmac\%C3\%AAutica +na+manipula\%C3\%A7\%C3\%A3o+de+medicamentos.+Art med+Editora\&ots=b4OMKLntVG\&sig=zDjXNuBitIKLQEhl ${ }^{\mathrm{R} 2}$ TeIyNpkM

6. Waterman, K.C. and Adami, R.C. 2005. Accelerated aging: prediction of chemical stability of pharmaceuticals. Int. J. Pharm. X. 293, 101-125.

7. Drug Bank, Desvenlafaxine. It was retrieved from https://www.drugbank.ca/drugs/DB06700

8. Dole, M.N., Minase, A.S., Chowdhary, S. and Sawant, S.D. 2013. Development and validation of analytical methods for estimation of desvenlafaxine succinate in bulk and solid dosage forms by UV spectroscopy. Der. Pharma. Chem. 5, 270-273.

9. Abirami, G., Logesh, R. and Vetrichelvan, T. 2011. Spectrophotometric method for estimation of desvenlafaxine succinate in tablet dosage form. Res. J. Pharma. Biol. Chem. Sci. 2, 721-729.

10. Chhalotiya, U.K., Patel, H.B. and Bhatt, K.K. 2010. Development and validation of an ultra performance liquid chromatography method for venlafaxine hydrochloride in bulk and capsule dosage form. Indian J. Pharm. Sci. 72, 814 .

11. Pawar, S.M. and Dhaneshwar, S.R. 2012. Application of stability indicating high performance thin layer chromatographic method for quantitation of desvenlafaxine in pharmaceutical dosage form. J Liq. Chromatogr. Relat Technol. 35, 499-510.

12. Mallikarjuna, R., Agarwal, N.K., Bichala, P.K. and Som, S. 2013. Method development and validation for the simultaneous estimation of desvenlafaxine and clonazepam in bulk \& tablet formulation by RP-HPLC method. Indian $J$. Res. Pharm. Biotech. 1, 525.
13. Rohith, T. and Ananda, S. 2012. Quantification of potential impurities by a stability indicating HPLC method in desvenlafaxine succinate monohydrate active pharmaceutical ingredient. Int. J. Res. Pharm .Chem. 2, 947-956.

14. Rajbangshi, J.C., Alam, M.M., Hossain, M.S., Islam, M.S. and Rouf, A.S.S. 2018. Development and validation of a RPHPLC method for quantitative analysis of linagliptin in bulk and dosage forms. Dhaka Univ. J. Pharm. Sci. 17, 175-182.

15. Sultana, S., Hossain, M.S., Islam, M.S. and Rouf, A.S.S. 2018 Quantitation of Sitagliptin in Drug Product by Validated Reversed Phase Liquid Chromatographic Technique. Dhaka Univ. J. Pharm. Sci. 17, 123-129.

16. Alam, M.M., Hossain, M.S., Bhadra, S., Kumar, U. and Rouf, A.S.S. 2017. Development and validation of RP-HPLC method for quantitation of clarithromycin in matrix tablet dosage form. Dhaka Univ. J. Pharm. Sci. 16, 69-75.

17. Sultana, S., Kumar, U., Hossain, M.S., Lira, D.N. and Rouf, A.S.S., 2017. QbD approach for the development and validation of RP-UHPLC method for quantitation of vildagliptin. Dhaka Univ. J. Pharm. Sci. 16, 107-117.

18. Rao, H., Ahmad, S., Madni, A., Ahmad, I. and Shahzad, M.N. 2020. Single-step extraction for simultaneous quantification of desvenlafaxine and alprazolam in human spiked plasma by RP-HPLC. Plos One. 15, p.e0238954.

19. Maher, H.M. and Belal, T.S. 2012. HPLC-DAD stability indicating determination of the fixed-dose combination of nifuroxazide and drotaverine hydrochloride in capsules. $J$ Liq. Chromatogr. Relat Technol. 35, 2001-2020.

20. Gawad, D.A. and Belal, T.S. 2017. HPLC-DAD stability indicating determination of pentoxyverine citrate. Application to degradation kinetics and assay of syrup dosage form. Arab. J. Chem. 10, S2908-S2918. 